Journal of Environmental
ISSN: $2525-815 \mathrm{X}$

\title{
Avaliação da qualidade hídrica de um rio do semiárido piauiense
}

\section{Evaluation of the water quality of a river in Piaui semi-arid}

\author{
Flávia Nycaelle Leal Costa ${ }^{a}$, Ykaro Richard Oliveira ${ }^{a}$, Paulo Henrique da Silva ${ }^{\text {a }}$, Paulo Michel \\ Pinheiro Ferreira ${ }^{\mathrm{a}}$, Ana Carolina Landim Pacheco ${ }^{\mathrm{a}}$, Maria Carolina de Abreu ${ }^{\mathrm{a}}$ \\ ${ }^{a}$ Universidade Federal do Piauí-UFPI, Campus Senador Helvídio Nunes de Barros-CSHNB. Rua Cícero Eduardo, S/N, \\ Bairro Junco, Picos, Piauí, Brasil. CEP: 64600-000. E-mail: fllavianycaelle@ hotmail.com, ykr-oliveira@ hotmail.com, \\ paulohenriquemh1@gmail.com, pmifepe@yahoo.com.br, carolandim@ufpi.br, mariacarolinabreu@hotmail.com.
}

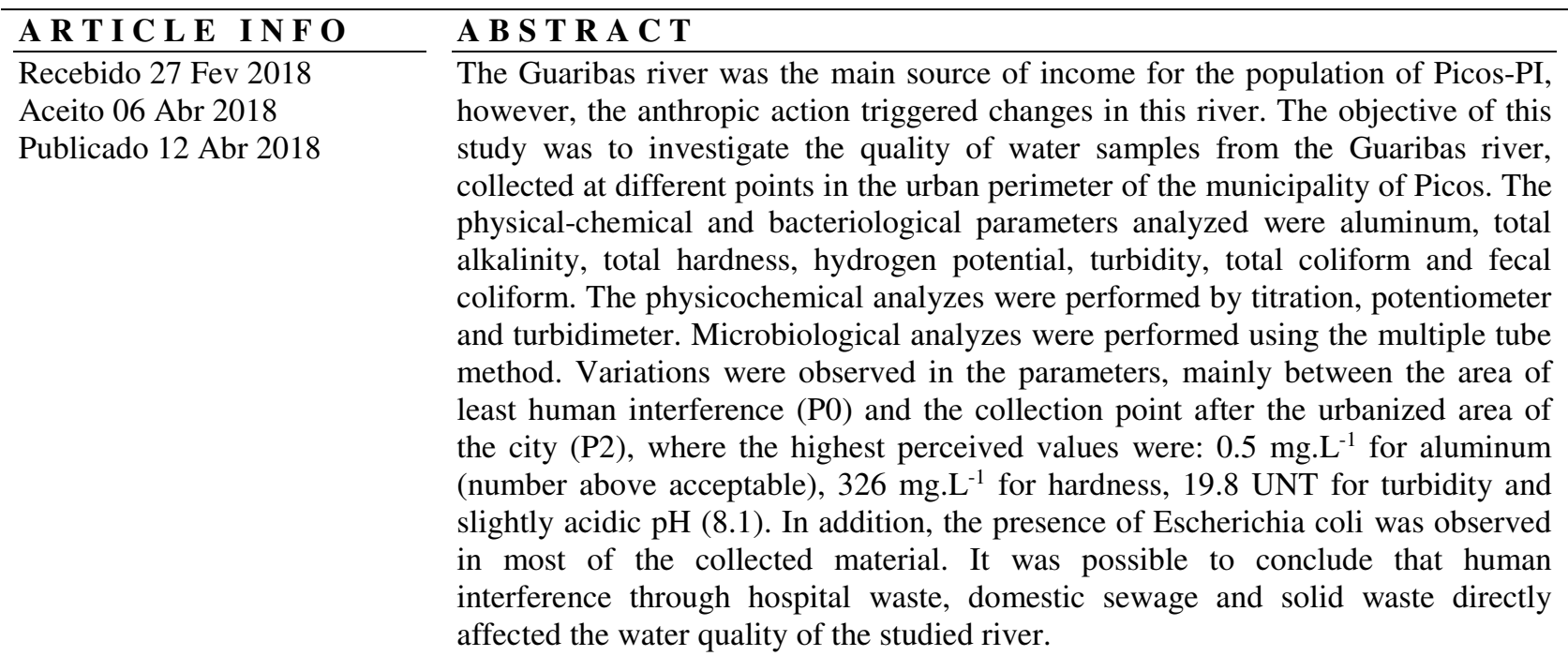

Keywords: Limnological aspects, water monitoring, Guaribas river.

\section{R E S U M O}

$\mathrm{O}$ rio Guaribas foi a principal fonte de renda para a população de Picos-PI, entretanto, a ação antrópica desencadeou mudanças no referido corpo d'água. $\mathrm{O}$ estudo objetivou averiguar a qualidade de amostras de água do rio Guaribas, coletadas em diferentes pontos no perímetro urbano do município de Picos. Os parâmetros físico-químicos e bacteriológicos analisados foram: alumínio, alcalinidade total, dureza total, potencial de hidrogênio, turbidez, coliformes totais e coliformes fecais. As análises físico-químicas foram realizadas por meio de titulação, potenciômetro e turbidímetro. As analises microbiológicas foram realizadas através do método dos tubos múltiplos. Foram percebidas variações nos parâmetros, principalmente entre a área de menor interferência humana (P0) e o ponto de coleta após a área urbanizada da cidade (P2), onde neste, os maiores valores percebidos foram: $0,5 \mathrm{mg} . \mathrm{L}^{-1}$ para o alumínio (número acima do aceitável); $326 \mathrm{mg} . \mathrm{L}^{-1}$ para a dureza; 19,8 UNT para a turbidez; pH levemente ácido $(8,1)$; além do mais, foi percebida a presença de Escherichia coli na maioria do material coletado. Foi possível concluir que q interferência humana através de dejetos de hospitais, esgotos domésticos e resíduos sólidos, afetaram diretamente a qualidade da água do rio estudado.

Palavras-Chave: Aspectos limnológicos, monitoramento de água, rio Guaribas.

\section{Introdução}

A água constitui um recurso indispensável à existência da vida no planeta e está presente em todos os segmentos da vida, sendo a substância mais ingerida pelo homem (Oliveira et al., 2017; Carvalho \& Recco-Pimentel, 2007). Além disso, é utilizada para diversas finalidades, como abastecimento doméstico e industrial, irrigação de 
produtos agrícolas, recreação, atividade pesqueira e geração de energia. Desse modo, nas últimas décadas, os recursos hídricos estão sendo cada vez mais disputados, principalmente em razão do acentuado crescimento demográfico e do desenvolvimento econômico (Brasil, 2002).

Embora seja um elemento essencial à vida, a água também pode trazer riscos à saúde, quando de má qualidade, servindo de veículo para vários agentes biológicos e químicos que, consequentemente, provocam doenças infecciosas e parasitárias. Por isso, o homem deve atentar para os fatores que podem interferir negativamente na qualidade da água de consumo e no seu destino final, uma vez que estes influenciam diretamente a saúde da população (Waldman et al., 1997; Barcellos et al., 1998; Rocha et al., 2006; Buzanello et al., 2008).

No Brasil, o problema não está na quantidade de água disponível, uma vez que é um país privilegiado neste aspecto, mas, sim, na qualidade e distribuição desta água. Deste modo, é fundamental um manejo adequado dos recursos hídricos para que seja possível o seu gerenciamento sustentável, assegurando a qualidade e a quantidade necessárias aos seus vários usos (Rolim Neto et al., 2013). Nesse aspecto, podem ser citados os estudos de: Amaral et al. (2003), Chaves et al. (2010), Friderichs et al. (2010), Costa et al. (2015), Oliveira et al. (2016) e Coelho et al. (2017), que evidenciaram a problemática da qualidade da água em território brasileiro.

Principalmente no semiárido brasileiro, a obtenção e a utilização da água de poços artesanais, rios, riachos e lagos, para o consumo humano, é comum, entretanto, esse tipo de fonte hídrica está sob um contínuo e crescente processo de degradação, em função do despejo de afluentes in natura ou tratados, de fezes de animais (silvestres e de produção), além dos materiais resultantes das atividades industriais (Dowbor, 2005).

Dados da Organização Mundial de Saúde (OMS) revelam que $80 \%$ das doenças nos países em desenvolvimento são causadas pela água contaminada (Coelho et al., 2007). Muitas doenças atribuídas à água e o elevado índice de internações hospitalares poderiam ser reduzidos com saneamento básico e conscientização da população em relação à preservação das águas superficiais e subterrâneas, de forma a disponibilizar a água com qualidade para o consumo direto e outros usos (Bastos et al., 2001).

Dentre as principais aplicações da água, o abastecimento público é a mais nobre e exigente, devendo ser considerada potável, ou seja, que atenda aos parâmetros microbiológicos, físicos, químicos e radioativos definidos pela legislação vigente e não ofereça riscos à saúde do consumidor (Sperling, 1996). Portanto, torna-se fundamental o monitoramento da qualidade da água, de modo contínuo, para que seja reduzida a ocorrência de enfermidades de veiculação hídrica, reduzindo maiores gastos com a saúde pública (Lima \& Santos, 2016).

Dessa forma, o objetivo deste estudo foi averiguar a qualidade de amostras de água do rio Guaribas, coletadas em diferentes pontos no perímetro urbano do município de Picos-PI, bem como avaliar as diferenças entre os parâmetros quantificados em diferentes locais de coleta e a relação existente com a influência antrópica sobre o rio.

\section{Material e Métodos}

Caracterização da área de estudo

$\mathrm{O}$ rio Guaribas compreende uma extensão de $47 \mathrm{~km}$ entre as coordenadas geográficas $\quad 07^{\circ} 04^{\prime} 37^{\prime} \mathrm{S} \quad-\quad 41^{\circ} 28^{\prime} 01^{\prime \prime} \mathrm{W}$, desaguando no rio Itaim, que faz parte da bacia do Guaribas. A bacia do Guaribas, na qual o rio em estudo é seu maior afluente, incorpora 18 municípios: Alagoinha do Piauí, Alegrete do Piauí, Bocaina, Campo Grande do Piauí, Francisco Santos, Fronteiras, Geminiano, Monsenhor Hipólito, Picos, Pio IX, Santana do Piauí, Santo Antônio de Lisboa, São João da Canabrava, São José do Piauí, São Julião, São Luís do Piauí, Sussuapara e Vila Nova do Piauí. Além do mais, por muitas décadas, o rio Guaribas foi o principal provedor hídrico para o desenvolvimento do município de Picos, servindo como geração de renda e abastecimento de água para a cidade (Silva Filho \& Gomes, 2004).

Segundo Lima et al. (2000), o município de Picos está localizado em uma região de clima semiárido, com base em seus parâmetros climáticos associados à vegetação, relevo, solo e hidrografia. São características desse domínio climático: uma precipitação média anual inferior à $900 \mathrm{~mm}$ e dois a três meses favoráveis à ocorrência de chuvas, com distribuição irregular no tempo e no espaço; temperaturas elevadas, com média anual de $27,3^{\circ} \mathrm{C}$, provocando um déficit hídrico que se faz presente em todos os municípios da região.

\section{Coleta e análise de dados}

Foram realizadas três coletas de amostras de água no rio Guaribas (Figura 1), em seu perímetro urbano do Município de Picos, em três diferentes locais (P0-Ipueiras, P1-Boa sorte e P2Canto da várzea) entre setembro de 2012 a março 
de 2013, onde cada ponto de coleta foi analisado três vezes durante a realização do experimento. Os procedimentos de amostragem foram feitos através de coleta simples, sendo o ponto de coleta acentuado a uma profundidade de, aproximadamente, $25 \mathrm{~cm}$ a partir da superfície.

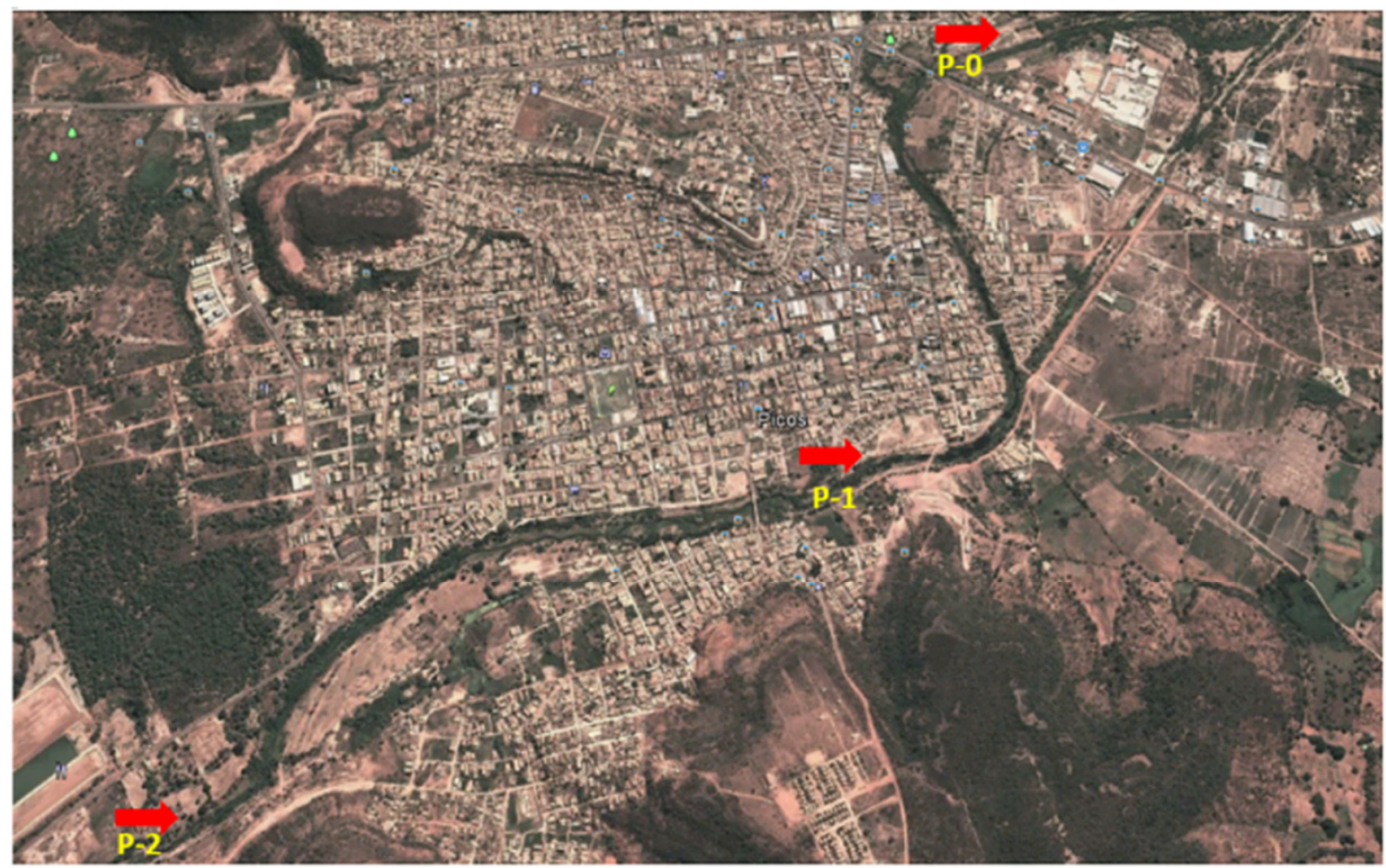

Figura 1. Pontos de coleta no município de Picos-PI. Fonte: Google Maps (2018).

Os índices de qualidade de água foram considerados conforme a Resolução $n^{\circ} 357$, de 17 de março de 2005, do CONAMA. Os parâmetros físico-químicos e bacteriológicos analisados foram: alumínio, alcalinidade total, dureza total, potencial de hidrogênio, turbidez, coliformes totais e coliformes fecais. As análises foram realizadas no Laboratório de Controle de Águas e Esgotos da AGESPISA, em Picos, de acordo com as técnicas preconizadas no Standard Methods for the Examination of Water and Wastewater (APHA, 1995).

As análises físico-químicas foram realizadas por meio de titulação, potenciômetro e turbidímetro. O parâmetro alumínio foi aferido por meio de titulação, onde foram utilizadas pipetas graduadas, tubos de nessler de $50 \mathrm{~mL}$, suporte para os tubos, solução padrão de alumínio, ácido acético a $30 \%$, hematoxilina e carbonato de amônia saturado. Foram colocados $50 \mathrm{~mL}$ da água da amostra em um tubo de nessler e em seguida preparou-se os padrões, colocando 0,2, 0,4, 0,5 e $1,0 \mathrm{~mL}$ da solução padrão em cada um dos tubos restantes, completando o volume com água destilada até $50 \mathrm{~mL}$. Juntou-se $1 \mathrm{~mL}$ de carbonato de amônia no tubo das amostras, sendo acrescentado $1 \mathrm{~mL}$ da solução de hematoxilina em cada tubo, e logo então, agitados por inversão. Em seguida, as soluções foram deixadas em repouso por $15 \mathrm{~min}$ e, posteriormente, foi adicionado $1 \mathrm{~mL}$ de ácido acético a $30 \%$ e o material foi novamente agitado para a comparação com os padrões, considerando a cor formada na parte superior do tubo.

Para a análise da alcalinidade total, por titulação, foi utilizada fenolftaleína, indicador metil orange e solução de ácido sulfúrico $50 \mathrm{~N}$. Em $100 \mathrm{~mL}$ da amostra foram adicionadas 10 gotas da solução de fenolftaleína, em seguida, colocou-se o ácido sulfúrico na bureta, e não havendo a mudança de cor, foram acrescentadas 6 gotas de metil orange. A titulação foi feita com o ácido sulfúrico até que ocorresse a mudança de cor das amostras. O resultado foi obtido pela quantidade de titulador que foi utilizado, multiplicado por 10 .

Para a análise da dureza total, por titulação, foram usados: cianeto de sódio (NACN), solução tampão, titulador EDTA e erichrome black. Inicialmente, foram separados $50 \mathrm{~mL}$ da amostra, adicionados 0,25 de cianeto de sódio e juntados a 0,2 de erichrome Black em cada amostra, depois ocorreu a adição de $1 \mathrm{~mL}$ de solução tampão e, quando a cor rosada mudou para azulada, o valor foi conferido e multiplicado por 20. 
Através da utilização do potenciômetro foi mensurado o potencial de hidrogênio $(\mathrm{pH})$ e a turbidez através de um Utilizando um turbidímetro. As análises microbiológicas foram realizadas através do método dos tubos múltiplos, a qual consiste do teste presuntivo e confirmativo. Para tal procedimento, 15 tubos de ensaio foram utilizados e distribuídos de 5 em 5.

Para $o$ teste presuntivo foram adicionados $10 \mathrm{~mL}$ do caldo lactosado no tubo de ensaio com o Durhan invertido e $10 \mathrm{~mL}$ da amostra, em seguida, a solução foi encubada na estufa a $37^{\circ} \mathrm{C}$, por 24 a 48 horas. Após esse período, ocorrendo a formação de gás dentro do tubo de Durhan, indicou-se que o teste presuntivo foi positivo, sendo necessária a realização do teste confirmativo. $\mathrm{O}$ teste confirmativo foi realizado nas amostras com resultado previamente positivo, no qual foram utilizados meios de cultura específicos para coliformes totais e coliformes fecais. Para tais métodos foi empregado o mesmo número de tubos do teste presuntivo positivados, contendo os meios de cultura. $\mathrm{Na}$ análise de coliformes totais foi aplicado o meio de cultura verde brilhante, de onde foram retiradas alíquotas de cada tubo positivado, utilizando a alça de platina, previamente flambada e fria, e inoculadas no tubo correspondente, contendo o meio de cultura. Estes tubos foram incubados em estufa a $35^{\circ} \mathrm{C}$, pelo período de 24 a 48 horas, e observados em dois momentos para averiguar a formação de gás no tubo Durhan.

Paralelo ao processo realizado para a identificação dos coliformes totais foi desenvolvida a técnica de assimilação dos coliformes termotolerantes, procedimento semelhante ao descrito anteriormente, no qual utiliza-se meio de cultura específico EC, e após inoculação, a incubação ocorreu em estufa na temperatura de $44,5^{\circ} \mathrm{C}$, durante 24 horas. Ao término, foi verificada a formação de gás dentro do tubo de Durhan, indicativo da presença de coliformes de origem fecal.

\section{Resultados}

Os índices de qualidade de água, bem como os parâmetros analisados, como: alumínio, alcalinidade, dureza, $\mathrm{pH}$, turbidez e coliformes totais e fecais foram preconizados conforme a Resolução $\mathrm{n}^{\circ}$ 357, de 17 de março de 2005, do CONAMA, e quando pertinente, tais dados foram dispostos em gráficos. Observando o teor alumínio nos diferentes locais, notou-se que os valores das concentrações apresentaram um aumento entre os valores obtidos no ponto inicial e no final, em todas as coletas (Figura 2).

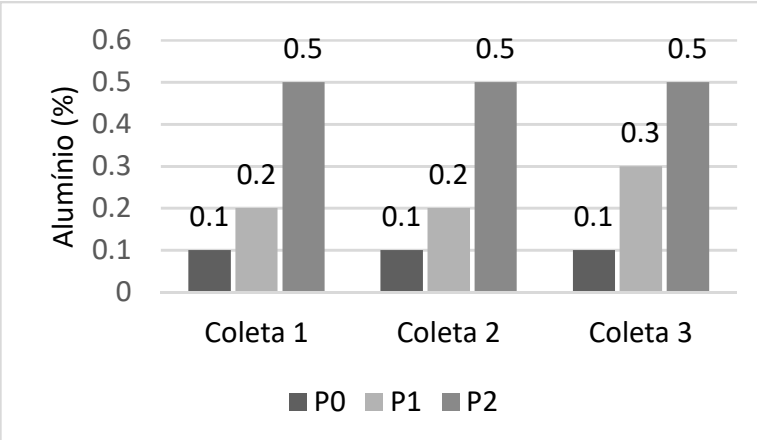

Figura 2. Percentual do alumínio nas amostras de água no córrego do Rio Guaribas, Piauí, em 2012/2013. Fonte: Autor (2018).

Logo, em P0 foram contabilizados valores iguais em todas as coletas $\left(0,1 \mathrm{mg} \cdot \mathrm{L}^{-1}\right)$, enquanto em P1 a concentração de alumínio foi a mesma em duas coletas $\left(0,2 \mathrm{mg} . \mathrm{L}^{-1}\right)$ e crescente na terceira coleta, com $0,3 \mathrm{mg} \cdot \mathrm{L}^{-1}$. Para P2, os valores obtidos foram uniformes nas três coletas, alcançando a concentração de $0,5 \quad \mathrm{mg} . \mathrm{L}^{-1}$, ultrapassando o valor máximo permitido pelo CONAMA no 357 (2005), que é de $0,2 \mathrm{mg} \cdot \mathrm{L}^{-1}$.

A alcalinidade medida neste estudo apresentou valores crescentes entre os pontos de coleta, fator esse que pode ser creditado à localização dos pontos das coletas, uma vez que estavam situados em areas com diferentes intensidades de urbanização, onde os pontos P1 e P2 estão sob maior descarga de efluentes advindos de hospitais, que despejam inúmeros resíduos, como substâncias ricas em boratos, silicatos, fosfatos e ânions orgânicos, que afetam a alcalinidade. Em P0, nas três coletas realizadas foram calculados os menores valores de alcalinidade, devido à sua localização apresentar baixa interferência humana e onde o nível de efluentes tem menor concentração.

Observando os períodos dos experimentos, a primeira e a terceira coletas foram realizadas no período de estiagem, enquanto a segunda deu-se no período chuvoso, contribuindo para a elevação dos valores dentre os demais percebidos para esse parâmetro. A Resolução CONAMA n 357 (2005) não faz menção a este parâmetro, não existindo especificações na legislação brasileira que estabeleçam os limites de alcalinidade em água. 


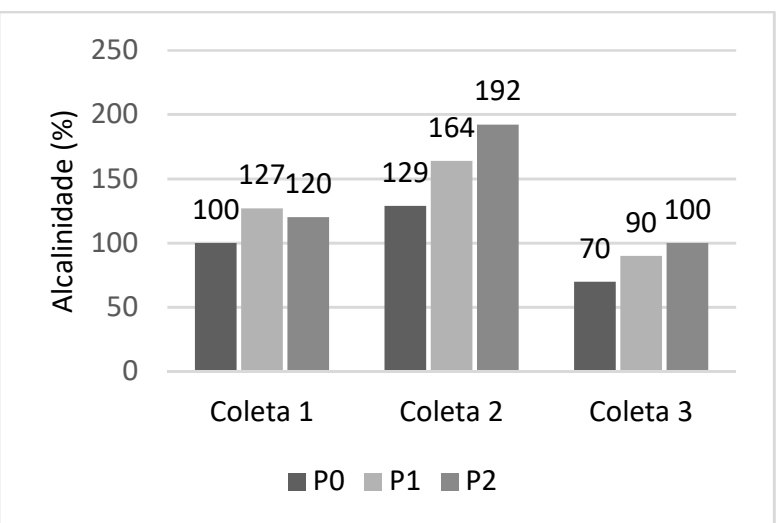

Figura 3. Percentual da alcalinidade total no córrego do Rio Guaribas, Piauí, em 2012/2013. Fonte: Autor (2018).

A análise da dureza da água (Figura 4) evidenciou uma variação entre os locais averiguados assim como entre as três coletas, não obstante, os maiores valores foram conferidos na segunda coleta (324 mg. $\mathrm{L}^{-1}$ e $326 \mathrm{mg} . \mathrm{L}^{-1}$ ), decorrentes do aumento da concentração de íons cálcio e magnésio, possivelmente carreados em materiais lixiviados no leito do rio.

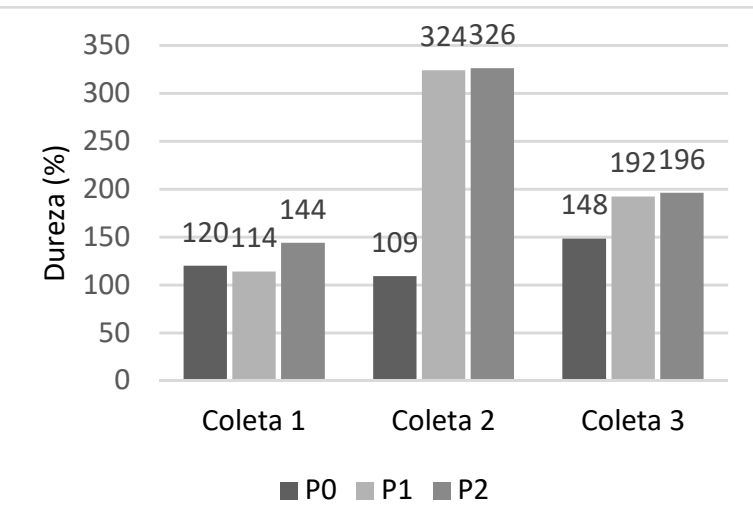

Figura 4. Percentual da dureza no córrego do Rio Guaribas, Piauí, em 2012/2013. Fonte: Autor (2018).

Quanto ao parâmetro pH (Figura 5), em P0 e P1 foram obtidos valores neutros, com variações de 7,0 a 7,5, enquanto em $\mathrm{P} 2$ foi determinada acidez nas amostras de água. Entretanto, esses números não ultrapassaram os padrões estabelecidos pela Resolução do CONAMA $n^{\circ} 357 / 05$, a qual estabelece limites de 6,0 a 9,0 .

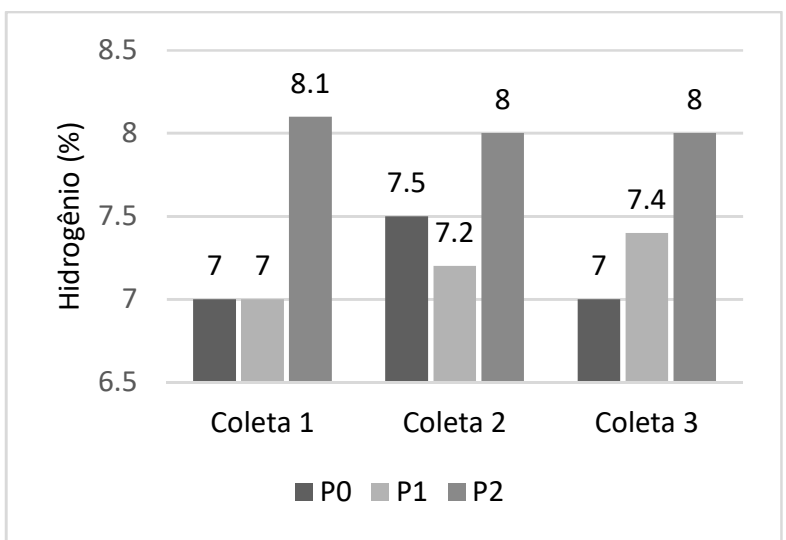

Figura 5. Percentual do potencial de hidrogênio do córrego do Rio Guaribas, Piauí, em 2012/2013. Fonte: Autor (2018).

Após análise do parâmetro turbidez (Figura 6), na primeira coleta, P0 apontou um valor de 1,64 UNT, enquanto P1 marcou 4,18 UNT e P2 apresentou um índice de 19,8 UNT. Na segunda coleta, os valores obtidos foram: 8,5 UNT em P0, 9,99 em P1 e 9,99 em P2, desse modo, foi percebida uma variação, principalmente com relação à coleta anterior. Na terceira coleta, todos os pontos marcaram o mesmo valor de 9,99 UNT. Vale ressaltar que, em todas as coletas, o P2 apresentou os maiores valores, entretanto, todos os valores para turbidez se enquadraram no limite estabelecido pela Resolução Conama $\mathrm{n}^{\circ} 357$ (2005) para corpos de água doce de Classe III (100 UNT). As diferenças entre os valores do parâmetro de turbidez podem ser explicadas pelo aumento de carregamento de partículas.

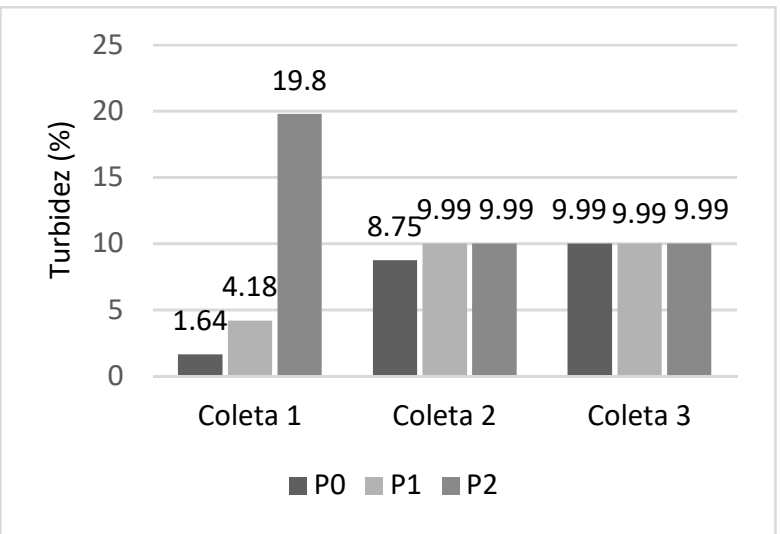

Figura 6. Percentual da turbidez no córrego do Rio Guaribas, Piauí, em 2012/2013. Fonte: Autor (2018).

As análises dos pontos seguiram um gradiente desde o ponto menos afetado para um de maior interferência dos efluentes, na malha urbana de Picos. Estas análises nos permitiram indicar que o P0 apresentou os menores valores de contaminação, provavelmente por apresentar uma menor interferência urbana, enquanto os índices 
de contaminação foram predominantes no P2, justificado pelo aumento das atividades econômicas, maior concentração de despejo de resíduos sólidos e efluentes não tratados.

\section{Discussão}

Considerando a concentração de alumínio, foi obtido um valor superior ao determinado pela CONAMA em um dos pontos de coleta, indicando que ao longo do rio existe a presença de metais pesados. O aspecto chave da química do alumínio é sua dissolução no solo para neutralizar a entrada de ácidos, desta forma, ele é extremamente tóxico à vegetação e pode ser escoado para os corpos d'água. A principal via de exposição humana não ocupacional é pela ingestão de alimentos e água, além do mais, o acúmulo de alumínio no homem tem sido associado ao aumento de casos de demência do tipo Alzheimer (IGAM, 2009).

A Resolução CONAMA no 357 (2005) não determina valores específicos para a alcalinidade, entretanto, é sabido que a sazonalidade é influente para esse parâmetro. Coelho et al. (2017) realizaram o monitoramento sazonal da qualidade da água de poços tubulares em uma comunidade rural de São Luís-MA e perceberam variação nos resultados das amostras com relação à época da coleta, onde valores mais elevados também foram encontrados no período chuvoso. Os autores mencionam que a alcalinidade da água é afetada pela presença dos íons hidróxidos, carbonatos e bicarbonatos, bem como pode ser derivada dos bicarbonatos.

Tais compostos, como o carbonato de cálcio, afetam a dureza da água, a exemplo, uma concentração de carbonato de cálcio abaixo de 50 mg. $L^{-1}$ é considerada a água como mole e de grande proveito para utilização direta, enquanto concentrações superiores a $150 \mathrm{mg} . \mathrm{L}^{-1}$ permitem a classificação da água como dura e seu uso requer tratamento de abrandamento, mediante sua aplicabilidade (Libâneo, 2005). A sensibilidade para a concentração da dureza na água, segundo Battalha \& Parlatore (1977), está frequentemente associada ao nível com o qual o consumidor está acostumado, podendo variar, por exemplo, de concentrações de carbonato de cálcio inferiores a $50 \mathrm{mg} . \mathrm{L}^{-1}$ a valores maiores que $200 \mathrm{mg} . \mathrm{L}^{-1}$.

Considerando o parâmetro $\mathrm{pH}$, apenas o ponto $\mathrm{P} 2$ apresentou acidez na água, com valor maximo de 8,1 , entretanto, esse valor se mantém aceitável pelas normas definidas para os corpos hídricos destinados ao abastecimento para consumo humano pela Resolução da CONAMA. Cruz et al. (2007), ao analisarem a água dos rios Parnaíba e Poty, observaram padrões semelhantes de $\mathrm{pH}$, sendo esse parâmetro muito influente sobre os ecossistemas aquáticos, uma vez que desempenha um efeito direto sobre a fisiologia de diversas espécies (CETESB, 1993).

Considerando a turbidez, Silva et al. (2015) analisaram um curso d'água no Município de Vigia, no nordeste do Estado do Pará e, segundo os autores, os valores da turbidez também se mostra inferiores ao limite determinados pela CONAMA. É evidente que altos valores de turbidez reduzem a fotossíntese da vegetação, enraizada submersa, e das algas. Esse desenvolvimento reduzido de plantas pode, por sua vez, suprimir a produtividade de peixes. Logo, a turbidez pode influenciar a comunidade biológica aquática e, além disso, afeta, adversamente, o uso doméstico, industrial e recreacional dos corpos d'água (CETESB, 2006).

No tocante às analises microbiológicas, somente na primeira coleta de P0 não foi detectada a presença de Escherichia coli; nos demais pontos amostrados pode-se notar a presença desta bactéria e, portanto, a presença de poluentes orgânicos se faz presente no rio, evidenciando a contaminação desse corpo d'água. Silva Neto \& Peixoto (2015) analisaram a água usada para o consumo humano em um Campus da Universidade Estadual do Tocantins no município de Palmas e, em $99 \%$ das amostras, a água se mostrou imprópria para o consumo devido a presença de E. coli.

As concentrações de coliformes termotolerantes apresentaram-se variáveis no período de monitoramento. Em todos os pontos amostrados foram encontrados indícios de contaminação, com exceção do $\mathrm{P} 0$ na primeira coleta. Entretanto, não é recomendável, mesmo em baixas concentrações, a presença de E. coli para a utilização da agua na recreação e no consumo humano (Gonçalves et al., 2005). A E. coli, principal bactéria dentre os coliformes fecais, subgrupo dos coliformes totais, é extensivamente utilizada no monitoramento da qualidade da água e são considerados os mais específicos indicadores de qualidade de águas destinadas à potabilidade e balneabilidade (Lopez-Pila \& Szewzyk, 2000; Nogueira et al., 2003; Lebaron et al., 2005).

\section{Conclusão}

A interferência humana, através de dejetos de hospitais, esgotos domésticos e resíduos sólidos, contribuiu para a poluição do Rio Guaribas, aumentando as concentrações dos coliformes totais e fecais, causando alterações nos parâmetros físico-químicos como alcalinidade, alumínio, $\mathrm{pH}$ e dureza. As alterações observadas interferem diretamente na qualidade da água, na 
existência de vida no leito do rio, assim como na utilização destas águas pela população.

O Rio Guaribas, segundo a Resolução CONAMA n ${ }^{\circ} 357$, de março de 2005 , pertencente à classe 3 , desta forma, a recomendação para o uso destas águas para abastecimento e para o consumo humano deve ocorrer após tratamento convencional ou avançado, podendo ser direcionado à irrigação de culturas arbóreas, cerealíferas e forrageiras, à pesca amadora, à recreação de contato secundário e à dessedentação de animais.

\section{Referências}

AMARAL, L. A.; NADER FILHO, A.; ROSSI JUNIOR, O. D.; FERREIRA, F. L. A.; BARROS, L. S. S. 2003. Água de consumo humano como fatos de risco à saúde em propriedades rurais. Revista de Saúde Pública, v. 37, n. 4, p. 510-514.

\section{AMERICAN PUBLIC HEALTH} ASSOCIATION. 1995. Standard methods for examination of water and wastewater. $19^{\mathrm{a}} \mathrm{ed}$. Washington: APHA.

BARCELLOS, C.; COUTINHO, K.; PINA, M. F.; MAGALHÃES, M. M.; PAOLA, J. C.; SANTOS, S. M. 1998. Inter-relacionamento de dados ambientais e de saúde: análise de risco à saúde aplicada ao abastecimento de água no Rio de Janeiro utilizando Sistemas de Informações Geográficas. Cadernos de Saúde Pública, v. 14, n. 3, p. 597-605.

BASTOS, R. K. X.; HELLER, L.; FORMAGGIA, D. M. E.; AMORIM, L. C.; SANCHEZ, P. S.; BEVILACQUA, P. D.; COSTA, S. S.; CANCIO, J. A. 2001. Revisão da Portaria 36 GM/90: Premissas e princípios norteadores. Anais XXI Congresso Brasileiro de Engenharia Sanitária e Ambiental, João Pessoa: Associação Brasileira de Engenharia Sanitária e Ambiental. pp. 1-12.

BATTAlHA, B. L.; PARLATORE, A. C. 1977. Controle da Qualidade da água para consumo humano. $2^{\mathrm{a}}$ ed. São Paulo: Gráfica CETESB.

BRASIL. 2002. Ministério do Meio Ambiente do Brasil. Avaliação das Águas do Brasil. Brasília, DF.

BUZANELLO, E. B.; BRUSCHI, E.; MARTINHAGO, M. W.; ALMEIDA, M. M.; PINTO, F. G. S. 2008. Determinação de coliformes totais e termotolerantes na água do Lago Municipal de Cascavel, Paraná. Revista Brasileira de Biociências, v. 6, n. 1, p. 59-60.
CARVALHO, H. F.; RECCO-PIMENTEL, S. M. 2007. A célula. $2^{\text {a }}$ ed. São Paulo: Manole.

CETESB. 1993. Controle da Qualidade da Água para Consumo Humano: Bases Conceituais e Operacionais. São Paulo.

CETESB. 2006. Determinaçao de fitoplâncton de água doce: métodos qualitativo e quantitativo: método de ensaio. Norma técnica, São Paulo.

CHAVES, K. F.; SILVA, N. B. N. da ; VIEIRA, T. B. ; MENDES, A. C. G.; GRAVINA, C. S.; MARTINS, A. D. O.; MARTINS, M. L. 2010. Avaliação microbiológica da água empregada em laticínios da região de Rio Pomba-MG. UNOPAR Científica. Ciências Biológicas e da Saúde, v. 12, n. 4 , p. 5-8.

COELHO, D. A.; SILVA, P. M. de F.; VEIGA, S. M. O. M.; FIORINI, J. E. 2007. Avaliação da qualidade microbiológica de águas minerais comercializadas em supermercados da cidade de Alfenas, MG. Revista Higiene Alimentar, v. 21, n. 151, p. 88-92.

COELHO, S. C.; DUARTE, A. N.; AMARAL, L. S.; SANTOS, P. M.; SALLES, M. J.; SANTOS, J. A. A.; SOTERO-MARTINS, A. 2017. Monitoramento da água de poços como estratégia de avaliação sanitária em Comunidade Rural na Cidade de São Luís, MA, Brasil. Revista Ambiente \& Água, v. 12, n. 1, p. 156-167.

CONAMA. Conselho Nacional do Meio Ambiente. Resolução $\mathrm{n}^{\mathrm{o}}$ 357, 2005. Disponível em: $\quad$ http://www.mma.gov.br/port/conama/. Aacesso em: 10/05/12.

COSTA, C. F.; AZEVEDO, C. A. S.; FERREIRA, S. de S.; MOURA, E. P. da S. 2015. Análise microbiológica da água do rio Itapecuru em Caxias, MA, Brasil. Revista Interface, n. 10, p. 274-283.

CRUZ, P.; REIS, L.; BARROS, A.; NEVES, J.; CÂMARA, F. 2007. Estudo Comparativo da Qualidade Físico-Química da Água no Período Chuvoso e Seco na Confluência dos Rios Poti e Parnaíba em Teresina/PI. Anais II Congresso de Pesquisa e Inovação da Rede Norte Nordeste de Educação Tecnológica, João Pessoa.

DOWBOR, L.; TAGNIN, A. 2005. Administrando a água como se fosse importante: gestão ambiental e sustentabilidade. São Paulo: Ed. Senac. 
FRIDERICHS, B. A.; ABREU N. F.; CALHEIROS, D. F.; CAMPOLIN, A. I.; SOARES, M. T. S. 2010. Qualidade da água utilizada para consumo em assentamentos rurais de Corumbá, MS. Circular Técnica, n. 96.

GONÇALVES, C. S.; RHEINHEIMER, D. S.; PELLEGRINI, J. B. R.; KIST, S. L. 2005. Qualidade da água numa microbacia hidrográfica da cabeceira situada em região produtora de fumo. Revista Brasileira Agrícola e Ambiental, v. 9, n. 3, p. 391-399.

IGAM. Instituto Mineiro de Gestão das Águas. 2009. Parâmetros Químicos. Disponível em: http://www.igam.mg.gov.br/. Acesso em: DATA.

LEBARON, P.; HENRY, A.; LEPEUPLE, A. S.; PENA, G.; SERVAIS, P. 2005. An operational method for the real-time monitoring of $E$. coli numbers in bathing waters. Marine Pollution Bulletin, v. 50, p. 652-659.

LIBÂNIO, M. 2005. Fundamentos de qualidade e tratamento de água. Campinas: Átomo, 2005.

LIMA, I. M. M. F.; ABREU, I. G.; LIMA, M. G. 2000. Semiárido piauiense: delimitação e regionalização. Carta CEPRO, v. 18, n. 1, p. 162183.

LIMA, S. C. A.; SANTOS, C. A. B. 2016. Educação e saúde pública: determinação de cloro e Escherichia coli, na água utilizada para consumo no IFPE, Campus Afogados da Ingazeira. Revista Ouricuri, v. 6, n. 2, p. 029-041.

LÓPEZ-PILA, J. M.; SZEWZYK, R. 2000. Estimating the infection risk in recreational waters from the faecal indicator concentration and from the ratio between pathogens and indicators. Water Research, v. 34, n. 17, p. 4195-4200.

SILVA NETO, L. K.; PEIXOTO, R. H. P. B. 2015. Qualidade microbiológica da água para consumo humano no campus da UNITINS no município de Palmas. Agri-environmental Sciences, v. 1, n. 2, p. 32-37.

ROLIM NETO, R. M.; BEZERRA, H. P.; CAMPOS, V. B.; SIQUEIRA, K. F.; ALMEIDA, W. L. 2013. Avaliação do sistema de tratamento e da qualidade das águas de abastecimento público em Laranjal do Jari, AP. Scientia Plena, v. 9, n. 11, p. 1-9.

NOGUEIRA， G.; NAKAMURA， C. V.; TOGNIM, M. C. B.; FILHO, B. A. A.; DIAS, B. P. F. 2003. Qualidade microbiológica de água potável de comunidades urbanas e rurais, Paraná. Revista de Saúde Pública, v. 37, n. 2, p. 232-236.

OLIVEIRA, A. F. S.; SILVA, L. D. P.; SILVA, T. M.; SANTOS, L. P.; ROCHA, R. M.; FREITAS H. G.; PEREIRA, S. F. P. 2017. Desenvolvimento do índice de qualidade da água bruta para fins de abastecimento público-IPA para Amazônia. Scientia Plena, v. 13, n. 1, p. 1-9.

OLIVEIRA, M. D.; CAMPOS, J. O.; FEIDEN, A. 2016. Características da água disponível para uso doméstico nos Assentamento 72, Ladário, Mato Grosso do Sul. Cadernos de Agroecologia, v. 11, n. 2, p. 1-5.

ROCHA, C. M. B. M.; RODRIGUES, L. S.; COSTA, C. C.; OLIVEIRA, P. R.; SILVA, I. J.; JESUS, E. F. M.; ROLIM, R. G. 2006. Avaliação da qualidade da água e percepção higiênicosanitária na área rural de Lavras, Minas Gerais, Brasil, 1999-2000. Cadernos de Saúde Pública, v. 22, n. 9, p. 1967-1978.

SILVA, E. R.; MARQUES, P.; SOUZA, E.; BARBOSA, I. C.; SILVA, A. 2015. Perfil físicoquímico e ecológico em um trecho do curso d'água do igarapé Santa Rosa, Município de Vigia (PA). Cadernos de Agroecologia, v. 10, n. 3.

SILVA-FILHO, J. S.; GOMES, J. M. A. 2004. Indicadores de bem-estar social nos municípios da bacia hidrográfica do rio Guaribas-Piauí. Anais II Encontro da Associação Nacional de PósGraduação e Pesquisa em Ambiente e Sociedade, Indaiatuba, Campinas.

SPERLING, M. V. 1996. Princípios básicos do tratamento de esgotos - Princípios do tratamento biológico de águas residuárias. Belo Horizonte, UFMG.

WALDMAN, E. A.; BARATA, R. C.; MORAES, J. C.; GUIBU, I. A.; TIMENETSKY, M. C. 1997. Gastroenterites e infecções respiratórias agudas em crianças menores de 5 anos, em área da região Sudeste do Brasil, 1986-1987. Revista de Saúde Pública, v. 31, n. 1, p. 62-70. 